\title{
Planning fundamental urban traffic changes: experiences with the Groningen traffic circulation scheme
}

\author{
S. Tsubohara ${ }^{1} \&$ H. Voogd ${ }^{2}$ \\ ${ }^{1}$ Prefectural University of Kumamoto, Japan \\ ${ }^{2}$ University of Groningen, Netherlands
}

\begin{abstract}
The city of Groningen in the Netherlands attracted much attention in the 1970s because of its fundamentally new traffic circulation scheme (VCP) that favoured public transport, bicycles and pedestrians above cars. The inner city was divided into four sectors and through traffic was made impossible by traffic restrictions. Moving by car from one sector to another is possible only via the ring road around the inner city. In this paper it will be explained how this fundamental change could happen. This was a most interesting process since the suspicious public had to be convinced by municipal authorities without having references to successful examples elsewhere. It is illustrated that the most determining factor for success was the availability of political power to neglect opposing views. Both expert involvement (bureaucracy) and citizen participation were reduced to a minimum level.
\end{abstract}

Keywords: traffic circulation scheme, Netherlands, Groningen, politicisation, polarisation, public participation.

\section{Introduction}

Urban Traffic Planning is often represented as a process that is largely shaped by technical means and rational approaches (e.g. see O'Flaherty [1]; Chowdhury and Sadek [2]). In literature on traffic planning, 'rationality', according to the Enlightenment tradition, is often considered well-defined, independent of context and its meaning is constant across time and space. However, Meyer and Miller [3] outline that infrastructure changes are mainly the consequence of choices in the political arena. They illustrate that rationality is context-dependent and that 
the crucial context is determined by decision-makers' power. Also Flyvbjerg [4] clearly demonstrates in his study of auto traffic reduction projects in the Danish city of Aalborg that rationality is but an ideal when confronted with the real rationalities involved in decision-making by central actors in government, economy and civil society. He shows that power is a very determining factor for change.

Evidently, the introduction of a fundamental change of an urban traffic structure is not an easy and straightforward process. The purpose of this paper is to explore this problem by an analysis of the introduction of a new traffic circulation scheme in the Dutch city of Groningen in the 1970s. This scheme favoured public transport, bicycles and pedestrians above cars and received worldwide attention (e.g. see Pharoah and Apel [5]). It divided the inner city into four sectors and through traffic was made impossible by the overall one-way traffic restriction (see Figure 1). Moving by car from one sector to another is possible only via the ring road around the inner city. The traffic circulation scheme (abbreviated here as VCP according to its Dutch name 'Verkeerscirculatieplan') included the construction of many bicycle-paths, the rebuilding of the Gedempte Zuiderdiep and Grote Markt, the drastic increase in the number of busses, and so on.

The introduction of such drastic changes was a most interesting process since the suspicious public had to be convinced by municipal authorities without having, in those days, good references to successful examples elsewhere in the Netherlands. A very elaborate description of this process, based on an exhaustive investigation of the 'day-by-day process' reconstructed from newspapers, local reports and interviews can be found in Tsubohara [6].

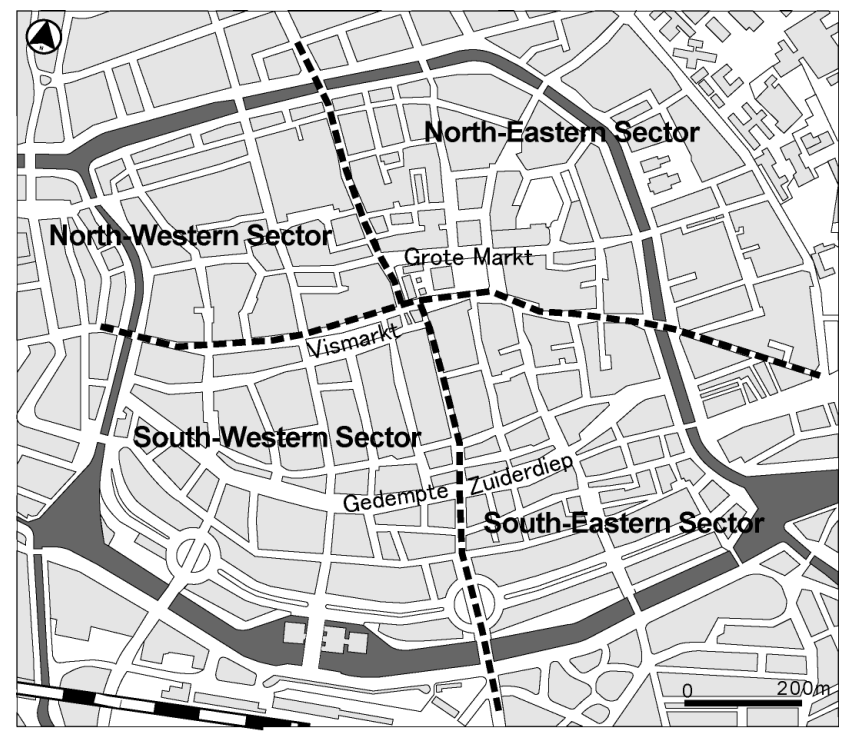

Figure 1: The sector division of the inner city of Groningen. 


\section{Major actors involved}

The planning process of the Groningen traffic plan began in the middle of the 1960 s and roughly ended with its 'one weekend' implementation in 1977. It was a process that originally started as a traditional rational planning process, but due to a strongly changed political environment the political arena soon dominated it. In this arena the following actors had been important: the national government, who should cover a major part of the investment costs of the scheme, the local government being the formal decision-taker, various economic interest groups, a citizens' pressure group and - last but not least - two local newspapers. This is elaborated in Figure 2.

Most opposition during the process came from economic pressure groups, which felt that their interests would be seriously harmed by the VCP. Especially the obstruction of car traffic raised a lot of anger, as it will be discussed in the following sections.

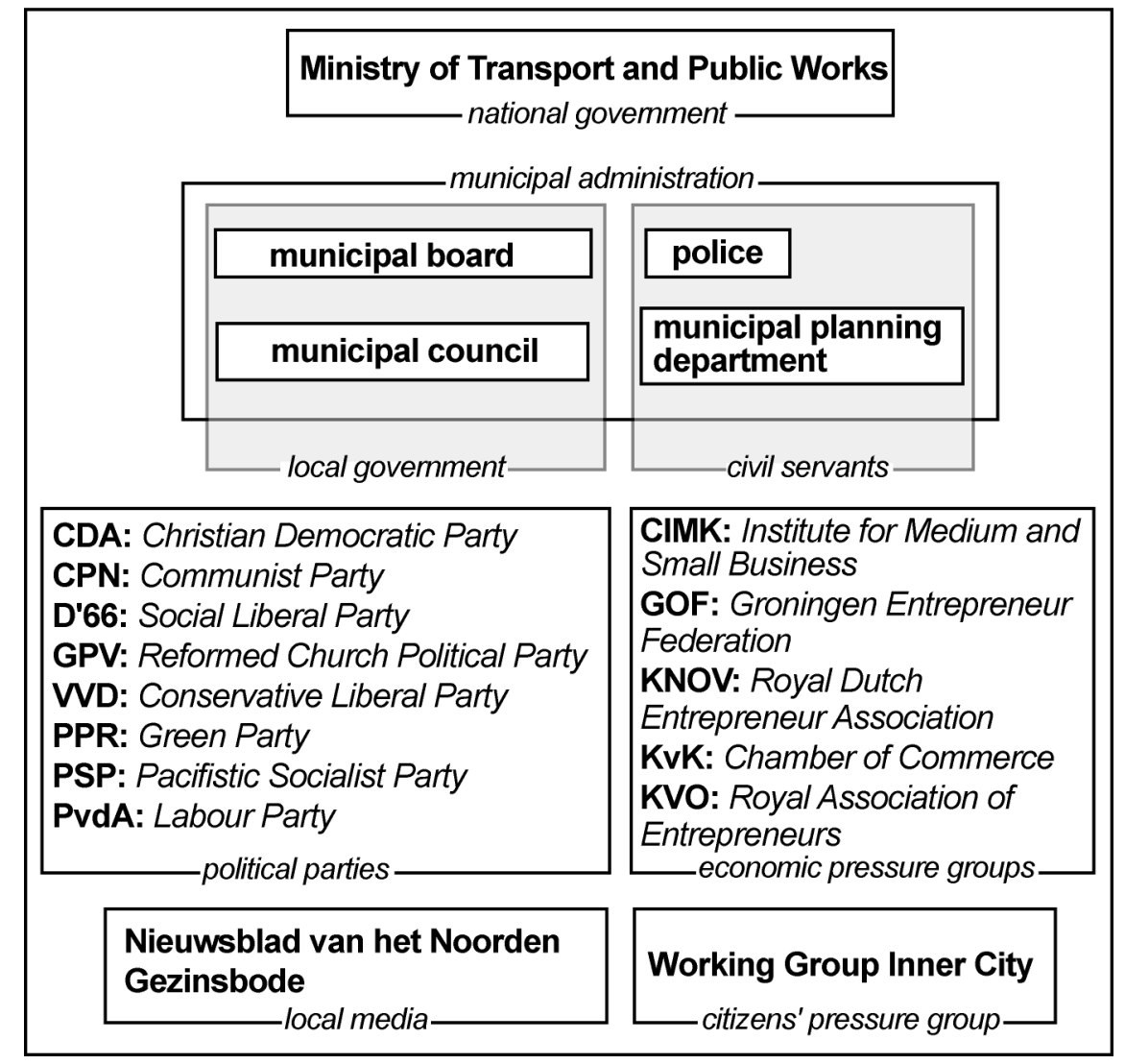

Figure 2: Important actors in the Groningen VCP planning process. 
Until the early 1970s the real power of municipal administration was concentrated at the experts within the civil servants. Under their initiative, the draft 'Structure Plan Groningen' of 1969 was published. They also drafted a series of plans for the inner city from the end of 1969 to early 1970. Among these, the 'Traffic Plan Centre Groningen' was based on the dramatic increase of car traffic. With the 'stream tangents' (trunk roads) next to the inner city, the plan would have caused the destruction of a large number of historical buildings. However, more or less a revolution happened in the field of politics and this revolution had finally brought about a fundamental change in urban planning.

In the municipal council of Groningen, the PvdA (Labour Party) had consistently been the biggest party since its establishment in 1946. However, lacking the successive alternation of generations of executives, it gradually declined into a party dominated by people from an older generation that grasped almost all the decision-making power within the party. The municipal board (or college van Burgemeester en Wethouders), however, had been organised so that it was the best representation of the council, giving also seats to the Christian parties and VVD (Conservative Party). It had put more emphasis on collegiality than on advocating each party's policy and competing with each other. It did not show any impetus to propose and pursue new policies. Instead, municipal civil servants had substantial power for policy making.

Since the middle of the 1960s this situation changed due to a movement within the PvdA called 'the new left'. The new left, consisting of 'angry young men and women', especially students of the University of Groningen, demanded that the discussion in the PvdA should be open and stimulating on one hand, and they criticised the modernist urban development by the municipality on the other hand. In the election of 1966 the PvdA fell to its lowest position, and renewed this worst record by losing even one more seat in 1970, leaving a total of only 13 seats. However, it then was rejuvenated totally, and chose a person of 25 years old, who just had received his degree in sociology and planning, as municipal board member He became responsible for the portfolio for transport, housing and urban development as well as culture. These young councillors of the PvdA claimed substantial power for policy making back from the civil servants (i.e. politicisation), pursuing their own policy without compromising with other parties (i.e. polarisation) and also claimed to involve the public substantially in the policy making (i.e. public participation). In other words, they tried to renew local governance. This attempt failed in the sense that public participation, despite good political intentions, hardly happened. The new left councillors on the other hand were quite successful with respect to politicisation and polarisation!

\section{The political context}

The new municipal board, which was installed in September 1970, was quickly thrown into confusion around how to deal with the above mentioned plans, just waiting to be proposed to the council. On May 10th, 1971, the board decided that, although it would propose the draft 'Structure Plan Groningen' of 1969 to 
the council without delay, it suspended other plans and, instead, would work out an utterly new planning principle for the inner city.

As an organisation to carry out this task, an 'Inner City Team' was established in May 1971. Besides municipal planners, four experts from outside joined in the team, and those experts took the initiative in drafting the planning principle. Via a 'Purposes Document' in October 1971 and a 'Criteria Document' in January 1972, the team submitted the 'Document Objectives Inner City Groningen', generally called the 'Objectives Document', in May 1972. This 'Objectives Document', which listed the goals and objectives to be pursued, showed a clear departure from the rational-technocratic planning approach and attracted nationwide attention because it implied a more explicit political involvement in planning. It advocated, among others, the principle of restraining car use on one hand, and giving priority to public transport, bicycles and pedestrians on the other hand. The municipal board was again thrown into confusion around this Objectives Document. This stalemate came to an end unexpectedly and drastically.

When the restrictive budget policy for 1973 was placed on the agenda of the board in September 1972, the young PvdA board member rejected discussion of it. According to him, the budget policy was an 'ad hoc' policy, not based upon a long-term plan. The Christian party groups, irritated by his repeated uncompromising attitude, moved a vote of no confidence against him in the council meeting of September 4th. However, all PvdA councillors opposed this. The CPN, D'66 and PSP also opposed, and the motion was rejected by 14 to 22 . In the face of this result, board members from the VVD and Christian party groups resigned their positions, saying that it was impossible to work with the young board member of the labour party. Hence the PvdA, based on the principle of polarisation, chose to form a new municipal board consisting of only left wing parties, who together had a very small majority in the council. The council approved this new municipal board by a narrow margin of 20 to 19 votes. The average age of the new board was 33, and, except for CPNers, in the 20s. This was the youngest and the first left municipal board among big cities in the Netherlands.

The new board proposed the Objectives Document to the council on November 14th, 1972. The council approved it on December 4th with the support of left wing parties (PvdA, D'66, PSP and CPN) by 22 to 17. With the decision of the Objectives Document, the new left got a theoretical-political foundation to pursue their planning policy.

The PvdA of Groningen had completed the political breakthrough with the election of May 1974. It placed the three young politicians (all around 26 years of age) on the first three places of the candidate list for the municipal council. This election, contrary to the previous one, gave the PvdA the biggest victory in its history with 18 seats, and this party again chose to form a municipal board based on a left majority with four PvdAers, one PPRer and one CPNer. The council approved this board on September 3rd, 1974, with right wing parties casting blank votes. The above-mentioned parties with seats in the municipal 
board occupied 23 seats of 39 in total. The VCP was planned and realised in this political context.

\section{Two central squares under debate}

The municipal board first made a separate effort to realise the 'Objectives Document' in terms of traffic policy. In July 1974 the discussion report 'Grote Markt' was published. This report suggested making the Vismarkt as well as the Grote Markt car-free through applying the 'loop system' to the surrounding roads. The parking spaces on the Vismarkt were abolished when the parking garage opened nearby on November 19th, 1974 and the square became a pedestrian area, including the south-bordering road.

In response to the efforts by the local government, in this period the public particularly paid attention to making the Grote Markt car-free. A citizens' group, the 'Working Group Inner City', had campaigned actively for it since 1973. It organised in 1974 a questionnaire survey for 500 citizens about their traffic modes or demands concerning traffic. According to the resulting report, bicycles were most used (37\%) as a traffic mode to the inner city, and $60 \%$ of the respondents supported making the Grote Markt car-free. After a demonstration by bicycle on the Grote Markt, the citizens' group submitted this report to the municipal board on November 20th, 1974.
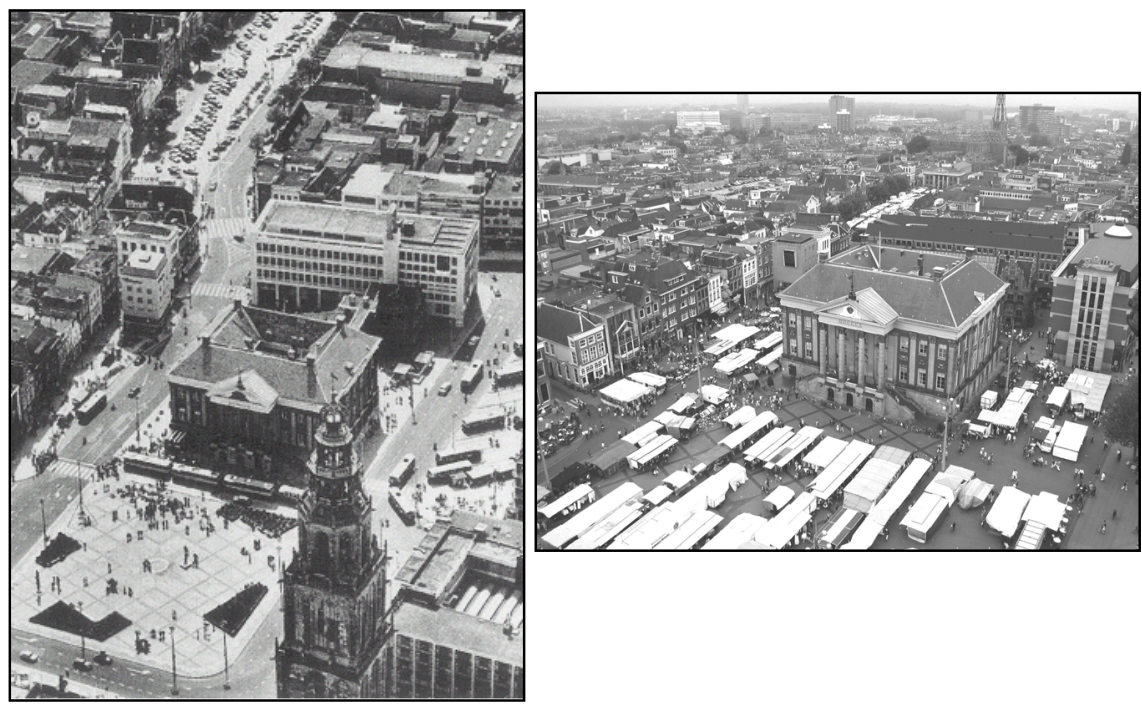

Figure 3: Grote Markt (in front) and Vismarkt (behind) of 1973 (left photo) and today (right photo).

Opposing opinions could also be heard at the end of 1974. They were perhaps stimulated by the fact that the shops along the Vismarkt, which was just made car-free, particularly along the closed southern road, suffered from a serious 
decline in profits. In response to the earlier-mentioned discussion report 'Grote Markt', the Chamber of Commerce (KvK) submitted a written opinion to the municipal board in which it asserted that the Grote Markt was too large to function as an attractive pedestrian area. It feared that the pedestrians would experience for the most part the Grote Markt as an "abandoned area". According to the Chamber of Commerce the car "forms an essential element in liveliness and colourfulness of the city centre".

In the municipal council, the CDA, among others, asked for a prudent approach to restricting car use. It did not appreciate the report by the citizens' group and criticised the group for "hoping to kick off cars from the city centre blindly".

\section{Towards a traffic circulation scheme (VCP)}

While the public attention still focused on the Grote Markt, the municipal board had, in fact, already set out to draft the VCP, covering the whole city area, in 1974. The direct beginning of the VCP was the letter from Minister Westerterp of the National Ministry of Transport and Public Works dated October 8th, 1973. There were at that time nine municipalities, including the city of Groningen, that operated their own public transportation companies, and all of them suffered from severe deficits. The letter noticed that the National Government would take over these deficits on the condition that each municipality should make a traffic circulation scheme (VCP) and submit it by January 1st, 1975. The gazette, dated April 24th, 1974, published the guideline for drafting the VCP.

The city of Groningen commissioned a large engineering consultancy bureau, Dwars, Heederik en Verhey (DHV) to draft the VCP in May 1974. The supervision of this activity was by the 'project group VCP', whose members were representatives of the police, the traffic planning bureau and town clerk's office.

The local newspaper 'Nieuwsblad' reported several times, particularly after October, that the VCP was being prepared and that it would be proposed in the middle of 1975 by the municipal board to the council. However, it did (or could) not mention its content at all, and the municipality itself did nothing to publicise it at the moment. As a result, the public, including shopkeepers, was hardly interested in the VCP. The national Ministry extended the deadline for the VCP to July 1st, 1975 at the municipality's request.

The public got the first opportunity to know about a part of the VCP when the first interim report, the 'VCP Groningen Basic Data', was published on February 27th, 1975. This report argued the necessity of the VCP saying, "the difficulties of the motorised traffic (congestion, stench, noise, parking problem, devouring of space, inaccessibility of services) have caused a harmful influence on the function of the society". But this report, as the title shows, did not touch on the concrete measures to be actually taken. However, the Nieuwsblad dated February 28th carried a big headline saying, "If traffic circulation scheme is implemented: there will be little place for the car in Groningen". This article started its first 
sentence by announcing, "The car will become the biggest 'victim', if the traffic circulation scheme for Groningen, which is now in preparation, is implemented".

The Nieuwsblad also gave prominent coverage to negative opinions by the police. Although the content of the scheme was not yet clear, business people had become gradually anxious through these newspaper articles.

The second interim report, the VCP Part II, was published on May 22nd, 1975. It mainly dealt with bus traffic. The municipal board tried to pick up two projects from this Part II and apply to them the national relief program for the unemployed, whose deadline was approaching. Criticism emerged from various parts of society about such a hasty procedure. The Working Group Inner City, which had made an effort to make the Grote Markt car-free, condemned the schedule for being "extremely undemocratic", in which the public meeting was held on May 31st, while the interim report was printed and made available on May 30th. The business groups, GOV and KvK, announced that they rejected attending the public meeting. The public meeting was held on May 31st as scheduled and about 100 people attended. However, only the prognosis of the traffic was explained then and nothing more. After this, there had been no opportunity for public participation for the VCP either. The municipal board repeatedly argued that they could not offer the opportunity for public participation, because the traffic circulation scheme (particularly public transport) would not be subsidised by the National Government, if the scheme was not submitted to the Ministry in a very short time.

The project group VCP completed the final draft of the VCP as early as in July 1975 , with no public participation. It proposed extending greatly the car-free area for the inner city. While at that time this draft was not published yet, a chief inspector of police condemned it in a local newspaper fiercely. His principal objections were that the scheme did not take account of traffic safety, legal and technical possibilities and the load- and discharge-problem of business in the inner city at all. The same article in the Nieuwsblad reported that many shops, as well as big companies, would become inaccessible for cars. This article caused strong anxiety and anger among business people. There was opposition against the draft even among municipal board members. The board decided to modify the draft on August 7th.

On August 13th, the extended project group, which was headed by the first responsible board member himself, set out the modification. According to the "myth" distributed by the local newspaper, this board member locked himself with a small group of faithful officials and outside advisers in the chapel of the Martini-church. When they came out, according to the local newspaper, "the notorious scheme with four sectors was born" - literally behind closed doors. While it reduced the car-free area dramatically, the modified scheme divided the inner city into four sectors by introducing the one-way traffic restriction overall. The municipal board on August 22nd approved unanimously this "much more realistic" scheme and fixed the date of proposing it to the council for September 15 th.

So residents and business people were confronted with two utterly different schemes in less than one month. Concerning the modified scheme, the local 
newspapers Gezinsbode and Nieuwsblad were almost the only way for the public to get acquainted with it. The Nieuwsblad reported on September 5th, 1975, "Criticism about the traffic circulation scheme continues to arrive at the city hall of Groningen."

On September 5th, 1975, for the first time an "information meeting" about the VCP was organised by the municipal board for business people. As this word shows, the objective was to inform, not to involve. More than 100 interested people attended, and raised a large number of criticisms and doubts. Particularly most of the criticism was directed at the lack of substantial participation, but the mayor responded, "The minister has put us on the spot concerning the available time. We must submit the scheme quickly; otherwise the subsidies come in danger." The "information meeting" for residents the next day, September 6th, did not attract much interest with, according to the Nieuwsblad, "only several tens of people". The VCP was proposed to the council on September 15th, with business people crowding in the gallery and on the steps of the city hall, holding up placards and banners. It was approved by 21 to 15 votes on September 17 th.

The VCP included the construction of many bicycle-paths, the rebuilding of the Zuiderdiep and Grote Markt, the drastic increase in the number of busses, and so on. Consequently, it was impossible to implement it without national subsidies. Because the municipality had difficulty in getting these subsidies, the start of the VCP took much more time than expected. However, the municipal board had held on to the VCP decided by the council, and the inner city was divided into four sectors literally in one night on September 19th, 1977.

\section{Evaluation}

The Groningen case shows that policy-making, administration, and planning are strongly interlaced activities, whereby power is a determining factor for success (see also Forester [7]; Ambrose [8]; Flyvbjerg [4]). In the process of realising the VCP of Groningen, the young new left politicians of the labour party dominated the municipal political arena. They pushed through their vision of a car-free inner city against the advice of civil servants and even the public. The new left had consistently rejected compromise with the nongovernment parties. The VCP was decided and started literally by sheer weight of numbers, while there remained conflicts in which the government parties supported and the nongovernment parties opposed. This uncompromising strategy was blamed as "dictatorial" by the nongovernment parties, while it was advocated and praised as "polarisation" by the new left.

Although the VCP would change the existing traffic behaviour fundamentally, there was hardly any involvement of the public in decisionmaking. In terms of the famous 'Ladder of Participation' of Arnstein [9], see Figure 4, public participation was pure tokenism. It is difficult to accept the explanation that the omission of participation was inevitable in order to draft and submit the VCP within the tight time limit imposed by the National Government, as frequently argued by the municipal board in those days. It has been elaborated in detail by Tsubohara [6] that the Ministry of Transport and Public Works at a 
certain point even demanded resumption in the procedure for participation but the municipal board rejected it.

\begin{tabular}{|l|c|c|}
\hline 8 & Citizen control & \multirow{2}{*}{ Citizens Participation } \\
\hline 7 & Delegated power & \multirow{2}{*}{ Tokenism } \\
\hline 6 & Partnership & \\
\hline \hline 5 & Placation & \multirow{2}{*}{ Non-participation } \\
\hline 4 & Consultation & \\
\hline 3 & Informing & \\
\hline 2 & Therapy & \multirow{2}{*}{ Non } \\
\hline 1 & Manipulation & \\
\hline
\end{tabular}

Figure 4: Arnstein's ladder of participation.

Nevertheless, it is interesting to notice that the National Government was used to put pressure on the kettle for avoiding proper citizen participation. It is doubtful if a similar result would have been possible in today's political context in which 'interactive plan making' and 'communicative planning' are considered as a necessary planning approach (Woltjer [10]). Given the opposition against the VCP it would have been more likely that a car-free inner city in Groningen still would not exist if the new left politicians did not act in an authoritarian way.

\section{References}

[1] O'Flaherty, C.A.(Ed), Transport Planning and Traffic Engineering, Butterworth-Heinemann, Oxford, 2001.

[2] Chowdhury, M.A. and A.W. Sadek, Fundamental of Intelligent Transportation Systems Planning, Artech House, Norwood MA., 2003.

[3] Meyer, M.D. and E.J. Miller, Urban Transportation Planning - A Decision-Oriented Approach, McGraw-Hill, New York (second edition), 2001.

[4] Flyvbjerg, B., Rationality and Power: Democracy in Practice, University of Chicago Press, Chicago, 1998.

[5] Pharoah, T. and D. Apel, Transport Concepts in European Cities, Ashgate Publishing, Aldershot, 1995.

[6] Tsubohara, S., Politicisation, Polarisation and Public Participation Planning History of Groningen, the Netherlands, in 1970's , URSI-report 302, Urban and Regional Studies Institute, University of Groningen, 2003.

[7] Forester, J.F., Planning in the Face of Power, University of California Press, 1989.

[8] Ambrose, P.J., Urban Process and Power, Routledge, London, 1994.

[9] Arnstein, S., A ladder of citizen participation, Journal of the American Institute of Planners, pp. 216-23, 1969.

[10] Woltjer, J., Consensus Planning, the relevance of communicative planning theory in Dutch infrastructure development, Ashgate Publishing, Aldershot, 2000. 